\title{
Module Temperature Dispersion Within a Large PV Array: Observations at the Amareleja PV Plant
}

\author{
Mikel Muñoz Escribano ， Miguel García Solano, Íñigo de la Parra Laita, Javier Marcos Álvarez, \\ Luis Marroyo \\ and Eduardo Lorenzo Pigueiras
}

\begin{abstract}
In-field photovoltaic (PV) module and array characterization is becoming increasingly important within the particular framework of quality assurance procedures at large commercial PV plants. In this context, the correct measurement of the module temperature is critical in order to reduce uncertainty and increase repeatability of results. In the case of large PV array characterization, the measurement provided by the sensors may not be representative of the PV array as a whole given the great diversity of operating conditions occurring throughout its surface area. Spatial temperature differences within a PV array of less than $5 \mathrm{~K}$ are typically considered in practice. However, the temperature differences observed at a commercial PV plant in Amareleja (Portugal) are more than twice those typically assumed. Such high differences may considerably increase the uncertainty in the determination of the PV array operating temperature and, hence, in its standard test conditions power characterization. This paper quantifies the uncertainty associated with the in-field measurement of the operating temperature of large PV arrays and their individual PV modules as a function of the type, number, and location of the temperature sensors used. Furthermore, the incident irradiance and particular wind speed conditions over the PV array have been clearly identified as the main causes of these temperature differences, showing that the optimum conditions to perform the PV array characterization do not correspond to low wind speed conditions, as recommended by many authors.
\end{abstract}

Index Terms-Dispersion, photovoltaic (PV) array, standard test conditions (STC) power, temperature, uncertainty, wind.

\section{INTRODUCTION}

A T A GLOBAL level, large-scale (utility-scale) photovoltaic (PV) plants are continuously growing in number [1], [2] and also in size, making quality increasingly difficult. The particular framework of quality assurance procedures (QAP) associated with the financing of these large PV plants is becoming increasingly important at the general PV scene. Low uncertainty and repeatability of results together with a short testing time are key aspects of the general QAP. Nowadays, the quality control of PV plants more often relies on the power control of samples of individual PV modules under standard test conditions (STC), carried out at specialized laboratories before in-field installation [3]-[7]. This makes it possible to guarantee the initial power delivered by PV manufacturers but does not exclude the subsequent occurrence of undesired phenomena such as initial light degradation, hot spots, polarization, etc. Moreover, it does not allow for the control of the power losses due to soiling, mismatch, and wiring. For this reason, some authors insist on the importance of the in-field characterization of PV modules and arrays [8]-[10], a practice that has already been included in the quality control procedures of a great number of commercial PV plants [8].

The measurement of actual operating conditions, i.e., the inplane irradiance of the modules $G_{I}$ and cell temperature $T_{c}$, forms the basis of the in-field PV module and array characterization. Seeking repeatability, the respective sensors used must behave like the PV array modules in terms of spectral, angular, and thermal response. In the case of PV module characterization, this is best accomplished by using "reference" modules placed near to the one to be measured [8], [11]. However, when the measured module is inside a large PV array, the question of where to position the reference module arises. Depending on the reference module location, the temperature conditions of that module and the measured one may be slightly different, thereby increasing the measurement uncertainty and reducing repeatability.

In the case of PV array characterization, the measurement provided by the sensors must be representative of the PV array as a whole. This leads to questions as to whether a single sensor is sufficient or which are the best locations for temperature sensors, given the diversity of operating conditions occurring throughout its surface area. This temperature dispersion causes the measurement uncertainty to increase, particularly with regard to large PV arrays. In order to reduce uncertainty, the international standard IEC-61829 [12] proposes measuring the temperature of several PV modules (at least three modules, whose operating temperatures are representative of the whole PV array) by attaching thermocouples to their backsheets. Indeed, the IEC 61853-1 standard [13] recommends fixing three thermocouples to each module in order to address the dispersion within the module itself. In the framework of the QAP at large PV plants, the procedures established in PV standards become unfeasible in terms of testing time. Thus, most of the available 
studies in the field of PV array characterization inside large PV plants were carried out by using reference modules to determine both the in-plane irradiance and the PV array operating temperature [8]. Consequently, in order to ensure low uncertainty and high repeatability, the temperature dispersion throughout the PV array and the location of the reference modules become key factors.

Seeking repeatability, clear sky moments are generally chosen for the measurements, as this normally ensures uniform irradiance on the PV array surface. However, this uniformity in irradiance does not guarantee temperature uniformity. The wind speed and wind direction have a direct influence on the temperature distribution across the array surface. Some authors maintain that a temperature inhomogeneity of less than $1 \mathrm{~K}$ can be expected in the absence of wind [14]. Thus, as a way to reduce the uncertainty in the determination of $T_{c}$ due to its spatial dispersion other authors have proposed that the measurements should be taken with wind speeds of less than $5 \mathrm{~m} / \mathrm{s}$ [15]. Nevertheless, it is not clear whether low wind speeds guarantee greater temperature uniformity.

Spatial temperature differences inside a PV array of less than $5 \mathrm{~K}$ are typically considered [11], [14]. However, an experiment carried out over two PV arrays in two different climates showed somewhat different results [16]. Maximum temperature differences of up to $10 \mathrm{~K}$ were found between the north and south ends of the PV arrays. In this case, the PV arrays comprised 60 copper indium gallium diselenide, glass-glass modules mounted on two racks positioned near the ground. A study was made of the possibility of the wind being responsible for these temperature differences, showing a slight influence of wind directionality on temperature gradient direction. Nevertheless, the authors could not entirely explain the observed trend by means of wind direction. They, thus, concluded that a different experimental design would be required to more fully explore wind as a factor and that it would be very interesting to do this analysis on other sites in order to determine whether these trends persist in different array configurations.

This paper presents the observations conducted on the temperature distribution of a $135 \mathrm{~m}^{2} \mathrm{PV}$ array comprising $104 \mathrm{c}-\mathrm{Si}$, glass-Tedlar modules, during an experiment carried out at a commercial 45.6 MWp PV plant in Amareleja (Portugal). The observed temperature distribution and the maximum spatial differences in temperature confirm those found by Farr and Stein [16]. However, in this case, it was possible to demonstrate a clear relationship between the temperature distribution and the wind conditions. The information provided by the observations presented herein makes it possible to determine the uncertainty associated with the in-field measurement of the operating temperature of PV modules and PV arrays and the influence of the number and location of the temperature sensors. These results are particularly relevant in the framework of QAP at large PV plants.

\section{EXPERIMENTAL SETUP}

The PV array under the study is one of the 2500 arrays forming part of the PV plant of Amareleja in Portugal (lat. $38.2^{\circ}$ ).

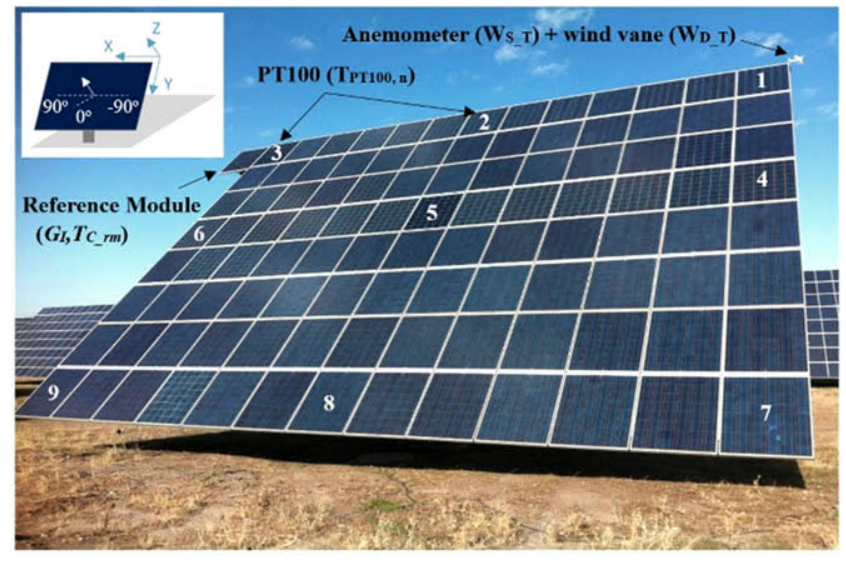

Fig. 1. Measurement device location in the PV array. The numbers indicate the PT100 sensor positions.

This plant has a peak power of $45.6 \mathrm{MWp}$ and covers a surface area of approximately 250 hectares. Each PV array is mounted on a vertical axis tracker (azimuthal tracking) and is tilted at an angle of $45^{\circ}$ in relation to the ground. The PV arrays have a rated power of $18.7 \mathrm{kWp}$ and comprise 104 glass-Tedlar, polycrystalline silicon modules. Their dimensions are $12.87 \times 10.48 \mathrm{~m}^{2}$, with a total surface area of $135 \mathrm{~m}^{2}$ (see Fig. 1). The plant is equipped with a weather station, which provide measurements of global horizontal irradiance $\left(G_{0}\right)$, diffuse irradiance $\left(D_{0}\right)$, ambient temperature $\left(T_{a}\right)$, wind speed $\left(W_{s}\right)$, and wind direction $\left(W_{d}\right)$.

In order to conduct a temperature distribution analysis across the PV array surface, PT100 sensors were mounted on the rear of nine modules, as shown in Fig. 1.

All the sensors were placed in the central area of the modules. Temperature measurements provided by those PT100 are named $T_{P T 100, n}$, where $n$ is the number of the corresponding PT100. A reference module located on one upper corner of the array is used to measure both the irradiance on the PV array plane and the cell temperature. Additionally, a wind vane with an anemometer was mounted on the other upper corner of the PV array, which provides wind speed $\left(W_{S_{-} T}\right)$ and wind direction $\left(W_{D \_}\right)$conditions on the PV array surface. Two different reference systems can be defined for the wind direction: the absolute N-S, E-W and a reference system relative to the PV array position. The letter is also represented in the upper left corner in Fig. 1(white). In this reference system, the wind direction is given by the angle formed by this direction and the horizontal projection of the $Z$-axis. Then, a $0^{\circ}$ angle means that the wind blows perpendicularly and a $90^{\circ}$ (or $-90^{\circ}$ ) angle means that the wind direction is parallel to the PV array surface.

The total temperature dispersion $\Delta T_{C}$ at a given moment is defined as the difference between the maximum and minimum values observed at all the PT100. It is also of interest to distinguish between "vertical" dispersion $\Delta^{V} T_{C}$, which is defined as the maximum difference between values observed in those PT100 located in the same vertical line (the same X component), and "horizontal" dispersion $\Delta^{H} T_{C}$, defined as the maximum difference between values observed in those PT100 located in the same horizontal line (the same Y component). 


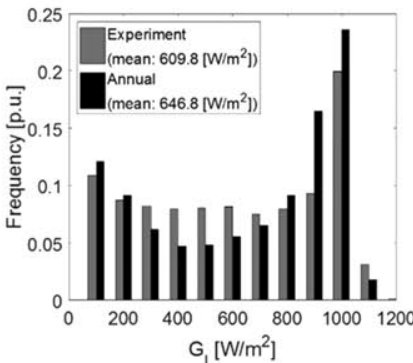

(a)

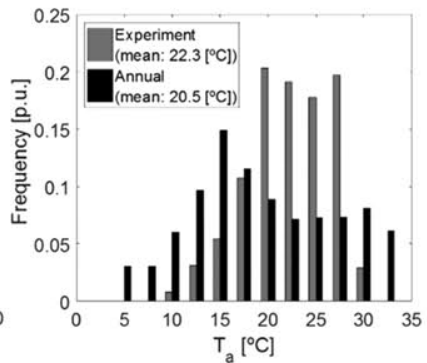

(b)
Fig. 2. (a) In-plane irradiance and (b) ambient temperature distributions during the experiment and during a whole year.

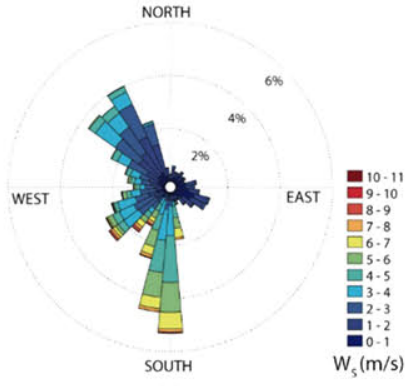

(a)

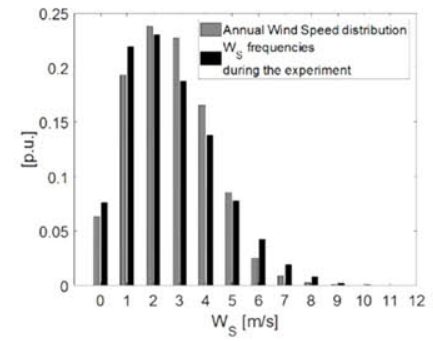

(b)
Fig. 3. (a) Wind conditions recorded at the weather station. (b) Wind speed distribution during the test and during a whole year.

\section{AMBIENT CONDITIONS DURING THE EXPERIMENT}

\section{A. Horizontal Irradiance and Ambient Temperature}

The experiment included clear days and days with variable cloudiness. The ambient temperatures recorded during the day ranged from $9^{\circ} \mathrm{C}$ to $30^{\circ} \mathrm{C}$. These conditions are representative of the ambient conditions recorded at the PV plant throughout the year. As shown in Fig. 2(a), the in-plane irradiance distribution during the experiment was similar to its annual distribution. Although the ambient temperature during the experiment was slightly different from the annual distribution, the mean values of both distributions were similar [see Fig. 2(b)].

\section{B. Wind Speed and Direction}

Wind speeds recorded at the weather station during the experiment were less than $7 \mathrm{~m} / \mathrm{s}$ for almost all the time with a predominantly southern direction for the first few days and then north-westerly for the last few days [see Fig. 3(a)]. Fig. 3(b) shows that the annual wind speed distribution is similar to the wind speed distribution during the experiment. Hence, the range of wind speeds recorded is fully representative of the annual wind conditions at the PV plant.

\section{Spatial Dispersion of the Wind Records}

In many PV practices, the wind speed is used to estimate the PV module temperature from the ambient temperature and the in-plane irradiance [16]-[19]. However, the wind records taken at a specific point of the PV plant (a weather station, for example) do not necessarily tie in with what is observed near

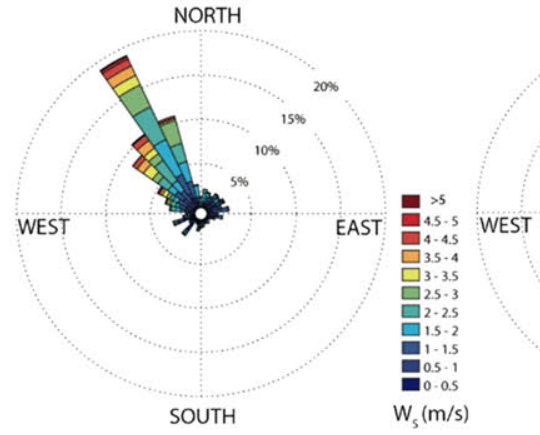

(a)

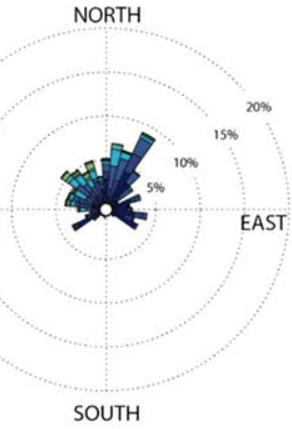

(b)
Fig. 4. (a) Wind conditions recorded at the weather station. (b) PV array anemometer.

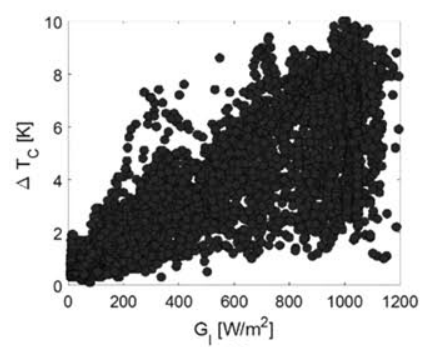

(a)

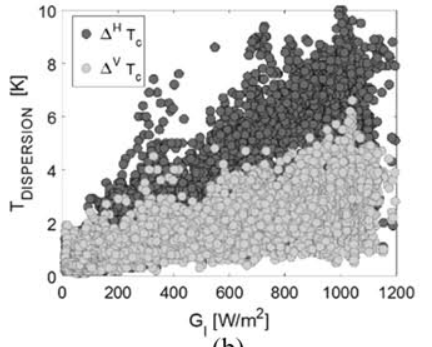

(b)
Fig. 5. (a) Maximum temperature dispersion versus irradiance. (b) Maximum temperature dispersion vertically (grey dots) and horizontally (black dots).

each PV array. Fig. 4 shows the wind measurements recorded at the weather station and those recorded at the anemometer mounted on the PV array itself. In order to correctly compare both records, the measurements taken on the PV array now refer to the N-S, E-W axes.

It can be seen how the direction of the wind on the PV arrays does not exactly match the direction recorded at the weather station. The speed is also lower. The PV array anemometer recorded maximum wind speeds of $4 \mathrm{~m} / \mathrm{s}$, whilst the maximum wind speeds recorded by the anemometer at the weather station were greater than $5 \mathrm{~m} / \mathrm{s}$. Thus, it is clear that the wind conditions at the PV arrays are modified to a certain extent by the surrounding environment. Consequently, the wind measurements recorded at a weather station located at a single point inside a large PV plant are not fully representative of the wind conditions at the different PV array surfaces and, therefore, their use in PV module temperature modeling entails considerable uncertainty.

\section{EXPERIMENTAL OBSERVATIONS}

\section{A. Temperature Dispersion Over the Entire PV Array Surface Area}

Fig. 5(a) shows the total temperature dispersion versus incident irradiance. The influence of irradiance on temperature dispersion appears to be clear. With low irradiance, the dispersion does not exceed 2-3 K, yet with irradiance values close to $1000 \mathrm{~W} / \mathrm{m}^{2}$, temperature differences of up to $10 \mathrm{~K}$ may occur between different points of the same PV array. Fig. 5(b) shows this dispersion in the vertical and horizontal directions. The observed horizontal dispersion is considerably larger than 


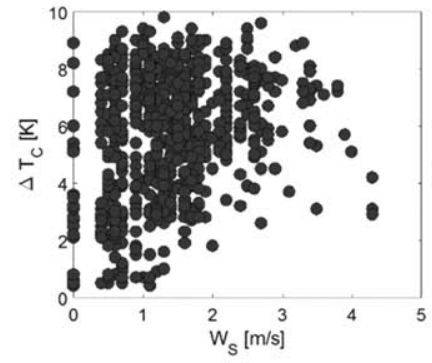

(a)

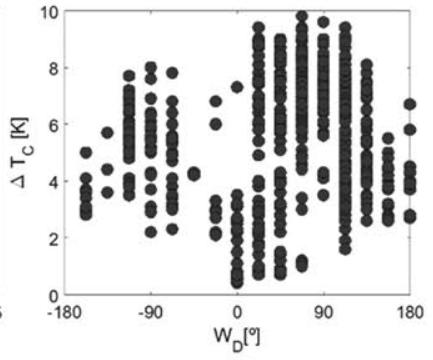

(b)
Fig. 6. (a) Maximum temperature dispersion versus wind speed. (b) Direction relative to the PV array position.

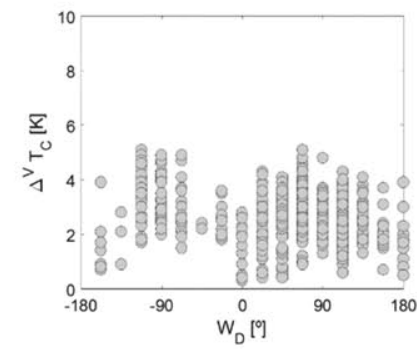

(a)

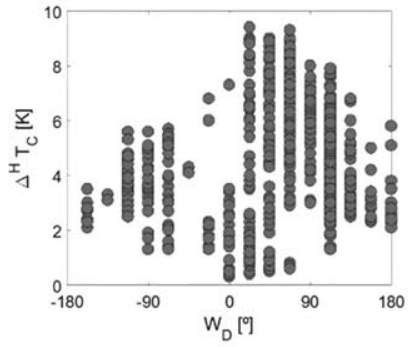

(b)
Fig. 7. Maximum temperature dispersion versus wind direction relative to the PV array. (a) Vertically. (b) Horizontally.

the vertical one. In fact, irradiance levels close to $1000 \mathrm{~W} / \mathrm{m}^{2}$ can reach a difference of $10 \mathrm{~K}$ horizontally and only 5 or $6 \mathrm{~K}$ vertically.

Those maximum horizontal dispersions observed during the experiment correspond to a temperature gradient of approximately $1 \mathrm{~K} / \mathrm{m}$. As a practical important effect for the in-field PV module characterization, the use of a single reference module fixed to one side of the PV array to estimate the temperature of individual modules could lead to an error of $1 \mathrm{~K}$ for every $1 \mathrm{~m}$ of horizontal distance between the reference module and the one to be measured. Since the power ratings of c-Si cell modules typically have temperature coefficients of around $0.5 \% / \mathrm{K}$, the increase of $1 \mathrm{~K} / \mathrm{m}$ in the temperature determination uncertainty represents an error increase in power of $0.5 \% / \mathrm{m}$.

\section{B. Influence of the Wind}

For the range of speeds between 0 and $3.5 \mathrm{~m} / \mathrm{s}$, the temperature dispersion ranged from $2-3$ to $10 \mathrm{~K}$. A dispersion lower than $5 \mathrm{~K}$ was found for wind speeds higher than $4 \mathrm{~m} / \mathrm{s}$, although the amount of data recorded for this range of wind speeds was very low. In any case, it is clear that low wind speeds do not guarantee greater uniformity in the temperature distribution of a PV array [see Fig. 6(a)].

The wind direction may exert a certain influence on the PV array temperature distribution for the low speed recorded [see Fig. 6(b)]. Fig. 7 shows the maximum temperature dispersion observed vertically [see Fig. 7(a)] and horizontally [see Fig. 7(b)], versus the wind direction (relative to the PV array position). The wind direction scarcely affects the vertical temperature distribution yet it does affect the horizontal

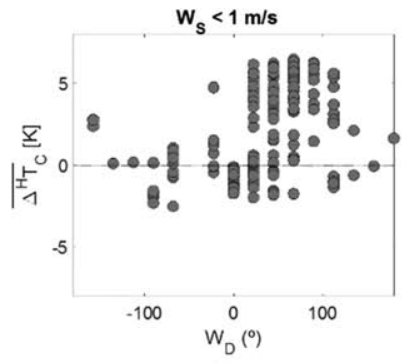

(a)

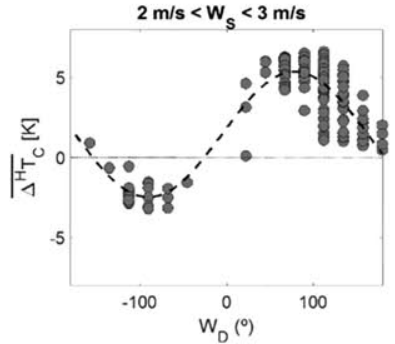

(b)

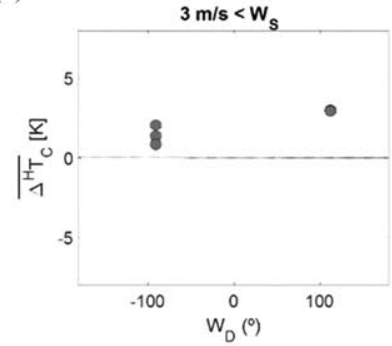

(c)

Fig. 8. Mean temperature difference between PV array ends versus wind direction relative to the PV array. (a) $W_{S}<0.5 \mathrm{~m} / \mathrm{s}$. (b) $2 \mathrm{~m} / \mathrm{s}<W_{S}<3 \mathrm{~m} / \mathrm{s}$. (c) $4 \mathrm{~m} / \mathrm{s}<W_{S}$.

distribution. The maximum dispersions are observed with wind directions of around $\pm 90^{\circ}$ (wind blowing parallel to the surface), whilst the smallest dispersions occur for directions of around $0^{\circ}$ and $180^{\circ}$ (wind blowing perpendicular to the surface). Note that Figs. 6(b) and 7(b) are very similar due to the fact that the maximum temperature dispersion is reached horizontally.

To better explain the influence of the wind direction on the horizontal temperature distribution, Fig. 8 shows the mean temperature difference between both PV array ends (right and left) versus the wind directions for different ranges of wind speeds. A clear correlation between temperature differences and wind direction can be observed in the range of wind speeds between 2 and 3 m/s [see Fig. 8(b)]. The maximum positive differences occur for a wind direction near $90^{\circ}$ (wind blowing parallel to the PV array from the left side), which means that the modules near the left end are cooler than those near the right end. The maximum negative differences occur for a wind direction near $-90^{\circ}$ (wind blowing parallel to the PV array from the right side), which means that the modules near the right end are cooler than those near the left end. The asymmetry in the positive and negative values is related to the different irradiance values recorded for each wind direction. Similar temperature differences can be observed for wind speeds below $1 \mathrm{~m} / \mathrm{s}$ [see Fig. 8(a)], although, in this case, there is no clear correlation with the wind direction. Temperature differences are smaller for wind speeds higher than $3 \mathrm{~m} / \mathrm{s}$ [see Fig. 8(c)] and no correlation with the wind speed is observed. However, as mentioned above, the amount of data recorded for this range of wind speeds was very low.

The above-mentioned results indicate that low wind speeds (typically below $3-4 \mathrm{~m} / \mathrm{s}$ ), combined with a given wind direction, promote the appearance of horizontal temperature gradients in the PV arrays, so that the modules closest to the direction in which the wind is blowing tend to be cooler. It seems reasonable to think that, with low speeds such as those recorded 


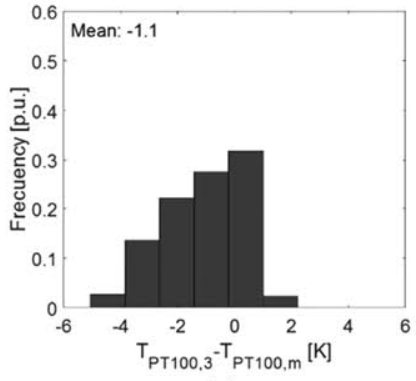

(a)

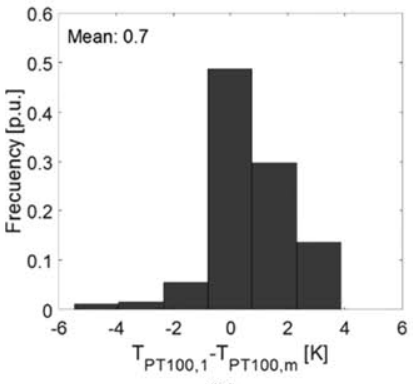

(b)
Fig. 9. (a) Histogram of the difference between the temperatures of the PT100 located at position $3, T_{\mathrm{PT} 100,3}$, and the average temperature of the nine PT100, $T_{\mathrm{PT} 100, \mathrm{~m}}$. (b) Histogram of the difference between the PT100 located at position $1, T_{\mathrm{PT} 100,1}$, and the average temperature of the nine PT100, $T_{\mathrm{PT} 100, \mathrm{~m}}$.

during the experiment, the airflow over the array surface would be closer to a laminar flow and with a more defined direction, whilst higher speeds would create a more turbulent airflow with no clear direction. It is likely that this second case would help to give a more uniform temperature across the surface. A more detailed and complex theoretical explanation for those phenomena can be found in the available literature [20].

\section{REPRESENTATIVENESS OF THE TEMPERATURE MEASUREMENTS}

In the framework of QAP and looking for simplicity, the infield characterization of PV arrays tends to be carried out by using the smallest reasonable number of temperature sensors. On many occasions, a single sensor attached to an accessible part of the PV array is used. Nevertheless, the temperature dispersion arising in a PV array can mean that the temperature measured at a single point is not fully representative of the overall temperature of the PV array. This is particularly the case of the temperature of the modules located on both sides of a PV array. The histograms in Fig. 9 show the difference between the measurement of the PT100 sensors located at both upper corners of the PV array $T_{P T 100,1}$ and $T_{P T 100,3}$ and the average of the nine temperatures recorded by the PT100 sensors $T_{P T 100, m}$. The mean value of these differences is around $1 \mathrm{~K}$. However, the dispersion ranges approximately from -4 and $+2 \mathrm{~K}$ in the histogram in Fig. 9(a) and from -2 and $+4 \mathrm{~K}$ in the histogram in Fig. 9(b). The asymmetrical shape of the histograms is specifically related to the position of each PT100 sensor on the PV array combined with the predominant wind direction during the test days. Thus, the total uncertainty in the temperature measured by a single sensor located at one of the corners of the PV array is, in fact, around $\pm 4 \mathrm{~K}$, which represents an uncertainty in the STC power of the PV array of approximately $\pm 2 \%$.

The uncertainty is considerably reduced if the temperature sensor is located at the center of the PV array. Indeed, Fig. 10(a) shows the difference between the PT100 located in the center $T_{P T 100,5}$ and the average of the nine PT100.

In this case, the asymmetry of the histogram has disappeared, and the average value has decreased to $0.2 \mathrm{~K}$, with a lower dispersion of around $\pm 2 \mathrm{~K}$. The uncertainty in STC power characterization is thus reduced to approximately $\pm 1 \%$. This

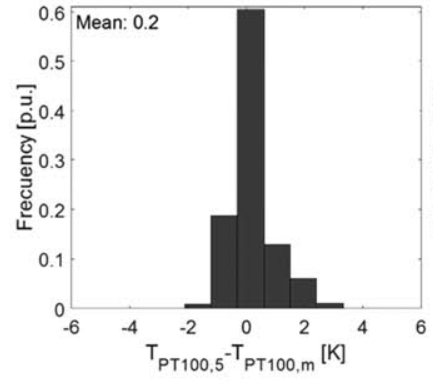

(a)

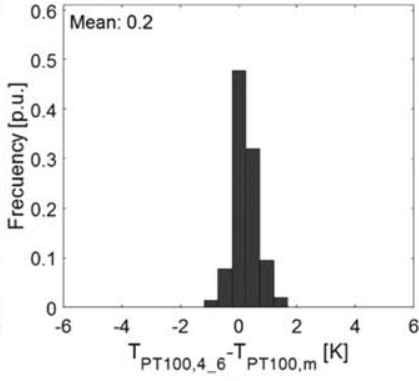

(b)
Fig. 10. (a) Histogram of the difference between the PT100 mounted in the center of the PV array, $T_{\text {PT100,5 }}$, and the average temperature of the nine PT100, $T_{\mathrm{PT} 100, m}$. (b) Histogram of the difference between the average temperature of PT100 located in the positions 4 and $6, T_{\mathrm{PT} 100,4-6}$, and the average temperature of the nine PT100, $T_{\mathrm{PT} 100, \mathrm{~m}}$.

observation reveals the importance of locating the temperature sensor as close as possible to the center of the PV array whenever high-accuracy in temperature determination is required. Nevertheless, if the temperature measurement is made by means of reference modules, locating one of those modules in the center of a PV array is impossible in practice. In that case, a better practice consists in the use of two reference modules fixed to both sides of the PV array (at midheight) and taking the mean of both measurements as the PV array $T_{c}$. Fig. 10(b) shows, precisely, the difference between the mean of the temperatures measured by the PT100 located on both sides of the PV array $T_{P T 100, m 4-6}$ and the average of the nine PT100. The mean value of these differences is also $0.2 \mathrm{~K}$ but the dispersion range is reduced to $\pm 1 \mathrm{~K}$, which represents an uncertainty in the STC power determination of only $\pm 0.5 \%$.

\section{CONCLUSION}

Instantaneous temperature differences of up to $10 \mathrm{~K}$ among the 104 modules of a PV array at the Amareleja PV plant (Portugal) have been observed. These temperature differences are more than twice the typically assumed differences and coincide with those previously observed in two PV arrays located in two different climate areas in the USA. Such high differences may considerably increase the uncertainty in the determination of the PV array operating temperature, especially if a single sensor is used for the measurements. These high differences may also considerably increase the dispersion losses of the PV array.

Contrary to what is commonly assumed, the maximum temperature differences occur with low wind speeds, normally less than $3-4 \mathrm{~m} / \mathrm{s}$. This calls into question the advantages of performing the in-field characterization of the STC power output of PV arrays with wind speeds of less than $5 \mathrm{~m} / \mathrm{s}$, as suggested by some authors.

The horizontal temperature dispersion can be almost double to that observed in a vertical direction due to the effect of the speed and direction of the wind on the convective processes taking place on the PV array surface. Low wind speeds, combined with a certain wind direction, promote the appearance of temperature gradients in the PV arrays, so that the modules closest to the wind direction tend to be cooler. 
The maximum temperature gradient observed horizontally was approximately $1 \mathrm{~K} / \mathrm{m}$. As a practical consequence, the use of a single reference module fixed to one side of the PV array to estimate the temperature of individual modules could lead to an error of $1 \mathrm{~K}$ for every $1 \mathrm{~m}$ of horizontal distance between the reference module and the one to be measured. This means an increase in the error of its STC power characterization of $0.5 \% / \mathrm{m}$, in the case of $\mathrm{c}-\mathrm{Si}$ modules.

The temperature provided by a reference module is more representative of $T_{C}$ than the measurement provided by a PT100. Nevertheless, the use of a single reference module for the PV array temperature determination may lead to high uncertainty in that measurement. If the reference module is located at one corner of the PV array, then the uncertainty in the temperature measurement can be around $\pm 4 \mathrm{~K}$ (i.e., approximately $\pm 2 \%$ in STC power). If the reference module is located in the middle of the PV array, then the uncertainty in the temperature measurement can be reduced to $\pm 2 \mathrm{~K}$, approximately ( $\pm 1 \%$ in STC power). As locating a reference module in the middle of a PV array is impossible in practice, the use of two reference modules fixed to either side of the PV array becomes a better practice. The uncertainty in the temperature measurement can be reduced to $\pm 1 \mathrm{~K}$ in this case, which represents an uncertainty of only $\pm 0.5 \%$ in the STC power determination.

\section{ACKNOWLEDGMENT}

The authors would like to thank ACCIONA for authorizing measurements at its PV plants and for the helpful collaboration of its staff.

\section{REFERENCES}

[1] Survey Report of Selected IEA Countries Between 1992 and 2015, "IEA PVPS trends 2016 in photovoltaic applications," International Energy Agency, Paris, France, Rep. IEA PVPS T1-30, 2016. [Online]. Available: $\mathrm{http} / /$ www.iea-pvps.org

[2] Solar Power Europe, "Global market outlook for solar power 2017-2021," 2014. [Online]. Available: http//www.solarpowereurope.org

[3] M. Alonso Abella, J. P. Silva, F. Fabero, N. Vela, and F. Chenlo, "PV module Peak power: Comparison between manufacturer data and laboratory results," in Proc. 23rd Eur. Photovolt. Sol. Energy Conf., Valencia, Spain, 2008, pp. 2837-2840.

[4] M. Alonso, J. P. Silva, F. Chenlo, F. Fabero, and N. Vela, "Aceptación de módulos fotovoltaicos para grandes centrales," in Proc. XIV Congr. Ibérico y IX Congr: Iberoamericano Energía Sol., Vigo, Spain, 2008, vol. 2, pp. 991-996.

[5] A. Steland and W. Herrmann, "Evaluation of photovoltaic modules based on sampling inspection using smoothed empirical quantiles," Prog. Photovolt., Res. Appl., vol. 18, pp. 1-9, 2010.

[6] J. Coello, L. Pérez, F. Domínguez, and M. Navarrete, "On-site quality control of photovoltaic modules with the PV MOBILE LAB," Energy Procedia, vol. 57, pp. 89-98, 2014.

[7] J. Coello, J. L. Galindo, M. Carames, and R. Carreño, "Quality control during the supply of PV modules: Fundamental key to guarantee the profitability of PV installations," in Proc. 23rd Eur. Photovolt. Sol. Energy Conf. Exhib., 2008, pp. 3784-3787.

[8] F. Martínez-Moreno, E. Lorenzo, J. Muñoz, and R. Moretón, "On the testing of large PV arrays," Prog. Photovolt., vol. 20, pp. 100-105, 2011.

[9] B. Farnung, P. Bostock, J. Bruckner, and K. Kiefer, "Complete PV power plant certification: New standards for quality assurance of large scale PV power plants," in Proc. IEEE 40th Photovolt. Spec. Conf., Denver, CO, USA, 2014, pp. 1917-1920.

[10] K. Kiefer, N. H. Reich, D. Dirnberger, and C. Reise, "Quality assurance of large scale PV power plants," in Proc. 37th IEEE Photovolt. Spec. Conf., Seattle, WA, USA, 2011, pp. 1987-1992.
[11] D. L. King, W. E. Boyson, and J. A. Kratochvil, "Photovoltaic array performance model," Sandia Nat. Lab., Albuquerque, NM, USA, Rep. SAND2004-3535, 2004.

[12] Crystalline silicon photovoltaic (PV) array-on-site measurements of I-V characteristics," IEC Standard 61829, 1995.

[13] "Photovoltaic (PV) module performance testing and energy rating - Part 1: Irradiance and temperature performance measurements and power rating," IEC Standard 61853-1, 2011.

[14] D. Dirnberger et al., "Uncertainty of field I-V-curve measurements in large scale PV-systems," in Proc. 25th Eur. Photovolt. Sol. Energy Conf. Exhib., 2010, pp. 4587-4594.

[15] E. Caamaño, E. Lorenzo, and R. Zilles, "Quality control of wide collections of PV modules: Lessons learned from the IES experience," Prog. Photovolt., Res. Appl., vol. 149, pp. 137-149, 1999.

[16] M. G. Farr and J. Stein, "Spatial variations in temperature across a photovoltaic array," in Proc. IEEE 40th Photovolt. Spec. Conf., Denver, CO, USA, 2014, pp. 1921-1927.

[17] D. Faiman, "Assessing the outdoor operating temperature of photovoltaic modules," Prog. Photovolt., Res. Appl., vol. 16, pp. 307-315, 2008.

[18] Y. Franghiadakis and P. Tzanetakis, "Explicit empirical relation for the monthly average cell-temperature performance ratio of photovoltaic arrays," Prog. Photovolt., Res. Appl., vol. 14, pp. 541-551, 2006.

[19] D. L. King, J. A. Kratovichil, W. E. Boyson, and W. I. Bower, "Field experience with a new performance characterization procedure for photovoltaic arrays," in Proc. 2nd World Conf. Exhib. Photovolt. Sol. Energy Convers., Vienna, Austria, Jul. 1998, pp. 1947-1952.

[20] H. Goverde et al., "Spatial and temporal analysis of wind effects on PV modules: Consequences for electrical power evaluation," Sol. Energy, vol. 147, pp. 292-299, 2017. 